\title{
HINTS KLINIKINIO TYRIMO SVARBA PERIFERINIO IR CENTRINIO TIPO SVAIGULIO DIFERENCINEI DIAGNOSTIKAI SKUBIOSIOS PAGALBOS IR PRIËMIMO SKYRIUJE
}

\author{
Kipras Medišauskas, Mantas Giedraitis, Darija Savinova, Augustas Kišonas \\ Lietuvos sveikatos mokslu universitetas, Medicinos akademija, Medicinos fakultetas
}

Raktažodžiai: svaigulys, periferinis svaigulys, skubiosios pagalbos ir prièmimo skyrius, HINTS.

\begin{abstract}
Santrauka
Svaigulys - dažnèjanti kreipimosi ị skubiosios pagalbos ir prièmimo skyrių priežastis. Svaigulio priežastis gali būti periferinè (pvz., vestibulinio aparato funkcijos sutrikimas) arba centrinè (pvz., galvos smegenų kraujotakos sutrikimas). Dažniausia svaigulio priežastis - periferinè, nekelianti pavojaus, tačiau kartais svaigulys gali būti gyvybei pavojingos būklès, tokios kaip kraujo išsiliejimas ị smegenų kamieną, įspejjamasis simptomas. Tyrimo tikslas - išsiaiškinti dažniausias periferinio svaigulio priežastis skubiosios pagalbos ir prièmimo skyriuje, jų požymius, esminius skiriamuosius bruožus HINTS tyrimo metu, diferencijuojant periferinès ir centrinès kilmès svaiguli. Literatūros paieška atlikta naudojantis LSMU virtualios bibliotekos prieiga prie elektroninių knygų bazès Vitae Litera ir medicinos mokslo žurnalų PubMed, ClinicalKey. Analizei atrinktos 24 publikacijos anglų kalba, paskelbtos 2011-2021 metų laikotarpiu.

Tyrimo rezultatai. Dažniausios trys svaigulio priežastys yra gerybinis paroksizminis pozicinis galvos svaigimas, vestibulinis neuritas ir Menjerio liga. Dažnai skiriamų vaizdo tyrimų diagnostinè vertè maža, kai nèra kitų neurologinių simptomų, išskyrus svaigulị. Detalus klinikinis tyrimas, papildytas paciento apklausimu apie susijusius veiksnius, laiko trukmę ir provokuojančias aplinkybes, yra tikslesnis būdas rasti teisingą diagnozę ir diferencijuoti periferinį svaiguli nuo centrinio, nei ankstyvoji KT ar MRT. Tinkamai atliekamo klinikinio galvos impulso, nistagmo ir žvairumo ištyrimo protokolo HINTS (angl. Head impulse, Nystagmus, Test of Skew) jautrumas diferencijuojant periferini ir centrinès kilmès svaiguli siekia 100 proc., specifiškumas 96 procentus [16]. Gerybinio paroksizminio pozicinio galvos svaigimo gydymo auksinis standartas išlieka Epley ir Semont manevrai, kuriu
\end{abstract}

efektyvumas siekia net 90 procentu.

Išvados. Klinikinis tyrimas HINTS yra specifiškas ir jautrus tyrimo būdas, kuris turètų būti taikomas svaigulio diagnostikai. KT ar MRT neturètų būti rutiniškai atliekami ị prièmimo ir skubiosios pagalbos skyrių dèl svaigulio atvykusiems pacientams, nesant kitų neurologinių simptomų.

\section{Ivadas}

Svaigulys - dažnėjanti kreipimosi ị skubiosios pagalbos ir prièmimo skyrių priežastis, sudaranti nuo 0,8 iki 4,0 proc. visų kreipimosi į PSPS priežasčių [1-4]. Šis simptomas apibūdinimas labai ịvairiai: svaigulys, kūno judesio pojūtis nesant judesio, nestabilumas ar aplinkos judejimas ịvairiomis kryptimis. Svaigulio priežastis gali būti periferinè (pvz. vestibulinio aparato funkcijos sutrikimas) arba centrinè (pvz. galvos smegenų kraujotakos sutrikimas). Nors dažniausia svaigulio priežastis periferinè, nekelianti pavojaus, tačiau kartais svaigulys gali būti gyvybei pavojingos būklès, tokios kaip kraujo išsiliejimas ị smegenų kamieną, ìspèjamasis simptomas [5-7], todèl reikalingas detalus ir nuoseklus ištyrimas, padėsiantis įvertinti grèsmingas būkles. Periferinio ir centrinio tipo svaigulys gydomas skirtingai, todèl svarbu atpažinti svaigulio tipą ir laiku skirti tinkamą gydymą. Šiame straipsnyje apžvelgiami naujausi duomenys apie dažniausias periferinio svaigulio priežastis, požymius, jų vertinimo ypatybes, KT ir MRT reikšmę diagnozès formavimui, klinikinị ištyrimą HINTS testu, padedančiu nustatyti teisingą diagnozę ir diferencijuoti periferinès kilmès svaiguli nuo centrinès.

Tyrimo tikslas - išsiaiškinti dažniausias periferinio svaigulio priežastis skubiosios pagalbos ir prièmimo skyriuje, jų požymius, esminius skiriamuosius bruožus HINTS ištyrimo metu, diferencijuojant periferinès ir centrinès kilmès svaiguli.

\section{Tyrimo medžiaga ir metodai}

Literatūros paieška buvo atlikta naudojantis LSMU vir- 
tualios bibliotekos prieiga prie elektroninių knygų bazès Vitae Litera, elektroninių žurnalų PubMed, ClinicalKey. Naudoti raktažodžiai: vertigo, acute diziness, acute vestibular syndrome, HINTS. Analizei atrinktos 24 publikacijos anglu kalba, paskelbtos 2011-2021 metų laikotarpiu.

\section{Tyrimo rezultatai}

Periferinio tipo svaigulys. Vestibulinis aparatas sudarytas iš trijų pusratinių kanalų (viršutinio, šoninio, užpakalinio) ir dviejų labirinto maišelių (lot. utricle, saccule). Kanaluose esančios endolimfos judèjimas dažnina arba retina aferentinio neurono perduodamų impulsų dažnị. Vienos pusès vestibulinio aparato perduodamų impulsų dažnis smegenyse lyginamas su kitos ir jų skirtumas interpretuojamas kaip judesys. Labirinto maišeliuose esantys otolitai atsakingi už gravitacijos ir tiesinio greitèjimo suvokimą [8]. Trys dažniausios priežastys, sutrikdančios šį mechanizmą, yra gerybinis paroksizminis pozicinis galvos svaigimas, vestibulinis neuritas ir Menjerio liga [9].

Gerybinis paroksizminis pozicinis galvos svaigimas ypatingo dèmesio reikalinga būklè, nes tai dažniausia (nuo 17 iki 42 proc. atvejų su vertigo simptomais [10]) efektyviai gydomo svaigimo priežastis. Vienos iš patofiziologinių teorijų teigimu, dèl galvos traumos ar vestibulinio organo pažaidos, maišeliuose esantys otolitai dislokuojasi ị pusratinius kanalus (90 proc. atvejų ị užpakalinị pusratinị kanalą). Šiuo atveju svaiguli provokuoja galvos judesiai, epizodai trunka iki minutès, intensyvumas pradžioje didèja, vèliau mažeja. Kartojant tą pati judesị, svaigulys tampa mažiau intensyvus, ar visai išnyksta. Tokio pobūdžio svaigulys nesusijęs su klausos sutrikimais ir kitais neurologiniais simptomais [11]. Gerybinio paroksizminio pozicinio galvos svaigimo gydymo auksinis standartas išlieka Epley ir Semont manevrai, kuriu efektyvumas siekia net 90 procentu $[9,12-14]$.

Vestibulinis neuritas diagnozuojamas 6 proc. prièmimo skyriaus pacientų, kurie skundžiasi galvos svaigimu, tačiau šis procentas, tikètina, turètų būti didesnis. Yra duomenų, kad Jungtinėse Amerikos Valstijose net 22 proc. pacientų išleidžiami esant nepatikslinto svaigulio diagnozei [15]. Tikètina, jog vestibulinị neuritą sukelia uždegiminis procesas VIII galvos nervo vestibulineje dalyje. Šis procesas išsivysto dèl virusinès infekcijos, tačiau tikslus mechanizmas vis dar nèra aiškus. Svaigulys gali trukti kelias dienas. Šio sutrikimo gydymas ūmioje fazėje simptominis, naudojant antiemetikus, antihistamininius ir benzodiazepinų grupès preparatus [16]. Rekomenduojama simptomini gydymą taikyti ne ilgiau nei 3 dienas, nes jis gali sukelti pakartotinius svaigulio epizodus [17]. Kortikosteroidų naudojimas kontroversiškas. Amerikos otorinolaringologų bendruomenès $2018 \mathrm{~m}$. publikuotame straipsnyje, kuriame apžvelgiami trys klinikiniai atsitiktinių imčių tyrimai ir viena sisteminè apžvalga, akcentuojama, jog nors daugumoje tyrimų stebimas trumpalaikis kortikosteroidų teigiamas poveikis, ilgalaikis poveikis vis dar neaiškus, todèl vertinant naudos-žalos santykị, nepakanka duomenų kortikosteroidų naudojimą rekomenduoti vestibulinio neurito atveju [18].

Menjerio liga - endolimfos kiekio padidèjimas vestibuliniame aparate, dèl kurio tempiami pusratiniai kanalai ir labirinto maišeliai, tad, padidejus slègiui, atsiranda svaigulys. Kas sukelia šį endolimfos kiekio padidejimą dar nėra žinoma. Svaigulys gali trukti nuo keleto minučių iki 24 valandų. Prieš pradedant gydymą, rekomenduojama diagnozuoti remiantis gairèmis ir klasifikacija, peržvelgta 2015 m. Equilibrium komiteto [18]. Gydymą tikslinga pradèti nuo gyvensenos ir rizikos veiksnių korekcijos (pvz. miego apnėjos sindromo gydymo, streso mažinimo). Dažniausiai naudojami medikamentai - diuretikai (hidrochlorotiazidas) ir antivertigo preparatai (betahistinas) [19].

Klinikinis tyrimas. Netikslinga pasikliauti ankstyvuoju KT ar MRT tyrimu. Yra duomenų, jog taikant tokią taktiką, didejja paciento vizito išlaidos [21], ilgèja gydymosi ligoninèje laikas [20], didèja gyvybei pavojingų būklių atmetimo rizika. Galvos smegenų KT dažnai daroma norint atmesti galimą kraujavimą i galvos smegenis, tačiau ji turi mažai diagnostinès reikšmès, kai nèra kitų neurologinių simptomų, išskyrus svaiguli [21]. Detalus klinikinis ištyrimas, papildytas paciento apklausimu apie susijusius veiksnius, laiko trukmę ir provokuojančias aplinkybes, pasirodė esąs tikslesnis būdas rasti paciento svaigimo priežastį, nustatyti teisingą diagnozę ir atmesti gyvybei pavojingas būkles, nei ankstyvoji KT ar MRT [22]. Tinkamai atliekamo klinikinio galvos impulso, nistagmo ir žvairumo ištyrimo protokolo HINTS (angl. Head impulse, Nystagmus, Test of Skew) jautrumas diferencijuojant periferini ir centrinès kilmès svaiguli siekia 100 proc., specifiškumas 96 procentus [16].

Galvos impulso tyrimas atliekamas pacientui sèdint priešais tyrejją. Paciento galva pasukama apie 20 laipsnių nuo vidurio linijos, tada tyrejas rankomis greitu judesiu pasuka galvą i vidurio liniją. Stebima, kaip pacientas geba fiksuoti žvilgsni i tyrèją viso pratimo metu. Jei fiksuoti žvilgsnio nepavyksta ir jis nukrypsta sukant galvą ị vieną pusę - testas teigiamas, būdingas periferinei etiologijai. Jei žvilgsnis nukrypsta pratimą darant $i$ abi puses, arba visai nenukrypsta - tai labiau būdinga centrinei etiologijai [23].

Nistagmas susideda iš greitos ir lètos fazès. Lèta fazè krypsta į pažeisto vestibulinio aparato pusę, o greitosios fazès kryptis nusakoma pavadinant simptomą (pvz., nistagmas i kairę). Spontaninis nistagmas laikomas periferinès priežasties, jeigu jis apibūdinamas kaip horizontalus ir vienpusis, o vertikalus ar dvipusis labiau būdingas centrinei etiologijai [24]. 
Žvairumo testas atliekamas pacientui esant priešais tyrèją. Tyrejjas uždengia ir atidengia po vieną paciento akị su ranka, kol pacientas bando laikyti fiksuotą žvilgsni i tyrejją. Paciento akių žvilgsnis turi išlikti simetriškas ir nežvairuoti viso testo metu. Žvairavimas, pastebètas šio testo metu, yra centrinès etiologijos požymis [25].

\section{Apibendrinimas}

Periferinè svaigulio priežastis yra dažnesnè, nei centrinė, tačiau kiekvienam pacientui turètų būti atliktas nuoseklus ir detalus klinikinis tyrimas, kad centrinè svaigimo priežastis galètų būti atmesta. Kokybiškai atliktas HINTS tyrimas gali padèti atmesti centrinès kilmès priežastį, taip sumažinant išlaidas ir paciento laiką prièmimo skyriuje. KT ar MRT tyrimas turètų būti skiriamas tik esant centrinès kilmès svaigulio požymių ar papildomų neurologinių simptomų.

\section{Išvados}

1. Dažniausia ị prièmimo-skubiosios pagalbos skyrių atvykstančių pacientų svaigulio priežastis yra periferinès kilmès (gerybinis paroksizminis pozicinis galvos svaigimas, vestibulinis neuritas, Menjero liga).

2. Periferinio svaigulio dažnis, charakteristika, gydymas priklauso nuo esamos ligos, tad priemimo-skubiosios pagalbos skyriuje parenkant preliminarią diagnose, atsižvelgtina i jos klinikinę išraišką.

3. KT ar MRT neturetų būti rutiniškai atliekami kiekvienam svaiguliu besiskundžiančiam pacientui. Tikslesnis būdas rasti svaigimo priežastị, nustatyti teisingą diagnozę ir atmesti gyvybei pavojingas būkles yra HINTS tyrimas, kuris turètų būti atliekamas pacientams, ị prièmimo-skubiosios pagalbos skyriu atvykusiems dèl galvos svaigulio.

\section{Literatūra}

1. Ljunggren M, Persson J, Salzer J. Dizziness and the Acute Vestibular Syndrome at the Emergency Department: A Population-Based Descriptive Study. Eur Neurol [Internet] 2018;79(1-2):5-12.

https://doi.org/10.1159/000481982

2. Edlow JA, Gurley KL, Newman-Toker DE. A New Diagnostic Approach to the Adult Patient with Acute Dizziness. J Emerg Med [Internet] 2018;54(4):469-83.

https://doi.org/10.1016/j.jemermed.2017.12.024

3. Royl G, Ploner CJ, Leithner C. Dizziness in the Emergency Room: Diagnoses and Misdiagnoses. Eur Neurol [Internet] 2011;66(5):256-63.

https://doi.org/10.1159/000331046

4. Newman-Toker DE, Hsieh Y-H, Camargo Jr CA, Pelletier AJ, Butchy GT, Edlow JA. Spectrum of dizziness visits to
US emergency departments: cross-sectional analysis from a nationally representative sample. Mayo Clin Proc [Internet] 2008;83(7):765-75.

https://doi.org/10.4065/83.7.765

5. Palmeri R, Kumar A. Benign Paroxysmal Positional Vertigo. StatPearls [Internet]. 2020. https://www.ncbi.nlm.nih.gov/ books/NBK470308/

6. Parker IG, Hartel G, Paratz J, Choy NL, Rahmann A. A systematic review of the reported proportions of diagnoses for dizziness and vertigo. Otol Neurotol 2019;40(1):6-15.

https://doi.org/10.1097/MAO.0000000000002044

7. Voetsch B, Sehgal S. Acute Dizziness, Vertigo, and Unsteadiness. Neurol Clin 2021;39(2):373-89.

https://doi.org/10.1016/j.ncl.2021.01.008

8. Lee AT. Diagnosing the cause of vertigo: a practical approach. Hong Kong Med J 2012;18(4):327-32.

9. Wipperman J. Dizziness and vertigo. Prim Care [Internet]. 2014;41(1):115-31. https://doi.org/10.1016/j.pop.2013.10.004

10. You P, Instrum R, Parnes L. Benign paroxysmal positional vertigo. Laryngoscope Investig Otolaryngol 2019;4(1):116-23. https://doi.org/10.1002/lio2.230

11. Imai T, Takeda N, Ikezono T, Shigeno K, Asai M, Watanabe $\mathrm{Y}$, et al. Classification, diagnostic criteria and management of benign paroxysmal positional vertigo. Auris Nasus Larynx 2017;44(1):1-6.

https://doi.org/10.1016/j.anl.2016.03.013

12. Mandalà M, Salerni L, Nuti D. Benign positional paroxysmal vertigo treatment: a practical update. Curr Treat Options Neurol 2019;21(12):1-18.

https://doi.org/10.1007/s11940-019-0606-x

13. Von Brevern M, Bertholon P, Brandt T, Fife T, Imai T, Nuti D, et al. Benign paroxysmal positional vertigo: diagnostic criteria. J Vestib Res 2015;25(3, 4):105-17. https://doi.org/10.3233/VES-150553

14. Bhattacharyya N, Gubbels SP, Schwartz SR, Edlow JA, ElKashlan H, Fife T, et al. Clinical practice guideline: benign paroxysmal positional vertigo (update). Otolaryngol Neck Surg 2017;156(3_suppl):S1-47. https://doi.org/10.1177/0194599816689667

15. Tarnutzer AA, Berkowitz AL, Robinson KA, Hsieh Y-H, Newman-Toker DE. Does my dizzy patient have a stroke? A systematic review of bedside diagnosis in acute vestibular syndrome. CmAJ 2011;183(9):E571-92. https://doi.org/10.1503/cmaj.100174

16. Smith T, Rider J, Cen S, Borger J. Vestibular Neuronitis. StatPearls [Internet] 2020.

17. Muncie HL, Sirmans SM, James E. Dizziness: approach to evaluation and management. Am Fam Physician 2017;95(3):154-62.

18. Solis RN, Sun DQ, Tatro E, Hansen MR. Do steroids improve recovery in vestibular neuritis? Laryngoscope 
2019;129(2):288-90

https://doi.org/10.1002/lary.27278

19. Nevoux J, Barbara M, Dornhoffer J, Gibson W, Kitahara T, Darrouzet V. International consensus (ICON) on treatment of Ménière's disease. Eur Ann Otorhinolaryngol Head Neck Dis 2018;135(1):S29-32.

https://doi.org/10.1016/j.anorl.2017.12.006

20. Kerber KA, Schweigler L, West BT, Fendrick AM, Morgenstern LB. Value of computed tomography scans in ED dizziness visits: analysis from a nationally representative sample. Am J Emerg Med 2010;28(9):1030-6. https://doi.org/10.1016/j.ajem.2009.06.007

21. Kerber KA, Newman-Toker DE. Misdiagnosing dizzy patients: common pitfalls in clinical practice. Neurol Clin 2015;33(3):565-75.

https://doi.org/10.1016/j.ncl.2015.04.009

22. Omron R. Peripheral vertigo. Emerg Med Clin North Am 2019;37(1):11-28.

https://doi.org/10.1016/j.emc.2018.09.004

23. Cohen HS. A review on screening tests for vestibular disorders. J Neurophysiol 2019;122(1):81-92. https://doi.org/10.1152/jn.00819.2018

24. Tarnutzer AA, Straumann D. Nystagmus. Curr Opin Neurol 2018;31(1):74-80. https://doi.org/10.1097/WCO.0000000000000517

25. Choi J-Y, Lee S-H, Kim J-S. Central vertigo. Curr Opin Neurol 2018;31(1):81-9.

https://doi.org/10.1097/WCO.000
ROLE OF HINTS CLINICAL ASSESSEMENT TO DIFFERENTIATE PERIPHERAL AND CENTRAL VERTIGO IN THE EMERGENCY DEPARTMENT

K. Medišauskas, M. Giedraitis, D. Savinova, A. Kišonas

Keywords: vertigo, peripheral vertigo, emergency department, HINTS.

Summary

Vertigo is a reason for emergency department visits that is increasing in frequency. The cause of vertigo can be peripheral (e.g. Vestibular organ dysfunction) or central (e.g. deprived blood delivery to the central nervous system). Even though the most usual cause of vertigo is peripheral, which is not a high-risk condition, it can be a sign of something more devastating like a hemorrhage in the brain stem. Three most frequent causes of vertigo: benign paroxysmal positional vertigo, vestibular neuritis, Maniere's disease. Performing advanced imaging has little diagnostic value to a patient that has isolated vertigo. This increases the length of stay in the hospital, increases the cost of care and falsely reassures providers of health care that life-threatening causes has been ruled out. A detailed physical assessment along with questioning about associated factors, timing and provocations is a more accurate way to diagnose and to differentiate between peripheral and central vertigo. Clinical assessment HINTS is a sensitive and specific way that should be applied and used for all patients with vertigo. CT and MRI should not be routinely performed to patients with vertigo without any other neurological findings.

Correspondence to: Kipras.medisauskas@gmail.com

Gauta 2021-05-30 